\title{
Application of Auxiliary VerifyNow Point-of-Care Assays to Assess the Pharmacodynamics of RUC-4, a Novel $\alpha$ llb $\beta 3$ Receptor Antagonist
}

\author{
Ohad S. Bentur ${ }^{1}$ Jihong $\mathrm{Li}^{1} \quad$ Caroline S. Jiang ${ }^{2}$ \\ ${ }^{1}$ Allen and Frances Adler Laboratory of Blood and Vascular Biology, \\ Rockefeller University, New York, New York, United States \\ 2 The Rockefeller University Hospital, New York, New York, United \\ States \\ ${ }^{3}$ The Carl and Edyth Lindner Center for Research and Education at the \\ Christ Hospital, Cincinnati, Ohio, United States
}

\author{
Linda H. Martin ${ }^{3}$ Dean J. Kereiakes ${ }^{3}$ Barry S. Coller ${ }^{1}$
}

TH Open 2021;5:e449-e460.

\author{
Address for correspondence Barry S. Coller, MD, The Rockefeller \\ University, 1230 York Avenue, New York, NY 10065, United States \\ (e-mail: collerb@rockefeller.edu).
}

\author{
Abstract \\ Keywords \\ - STEMI \\ - platelet aggregation \\ inhibitors \\ - point-of-care testing \\ - platelet glycoprotein \\ GPIIb-IIla complex \\ - acute myocardial \\ infarction
}

Introduction Prehospital therapy of ST-elevation myocardial infarction (STEMI) with allb $\beta 3$ antagonists improves clinical outcomes, but they are difficult to use in prehospital settings. RUC-4 is a novel $\alpha$ llb $\beta 3$ antagonist being developed for prehospital therapy of STEMI that rapidly achieves high-grade platelet inhibition after subcutaneous administration. Standard light transmission aggregometry (LTA) is difficult to perform during STEMI, so we applied VerifyNow (VN) assays to assess the pharmacodynamics of RUC-4 relative to aspirin and ticagrelor.

Methods Blood from healthy volunteers was anticoagulated with phenylalanyl-prolylarginyl chloromethyl ketone (PPACK) or sodium citrate, treated in vitro with RUC-4, aspirin, and/or ticagrelor, and tested with the VN ADP $+P E_{1}$, iso-TRAP, and base channel (high concentration iso-TRAP + PAR-4 agonist) assays. The results were correlated with both ADP $(20 \mu \mathrm{M})$-induced LTA and flow cytometry measurement of receptor occupancy and data from individuals treated in vivo with RUC-4.

Results RUC-4 inhibited all three VN assays, aspirin did not affect the assays, and ticagrelor markedly inhibited the ADP $+\mathrm{PGE}_{1}$ assay, slightly inhibited the iso-TRAP assay, and did not inhibit the base channel assay. RUC-4's antiplatelet effects were potentiated in citrate compared with PPACK. Cut-off values were determined to correlate the results of the VN iso-TRAP and base channel assays with $80 \%$ inhibition of LTA.

Conclusion The VN assays can differentiate the early potent anti- $\alpha$ llb $\beta 3$ effects of RUC-4 from delayed effects of P2Y12 antagonists in the presence of aspirin. These pharmacodynamic assays can help guide the clinical development of RUC-4 and potentially be used to monitor RUC-4's effects in clinical practice. received

January 28, 2021

accepted

June 16, 2021
DOI https://doi.org/

10.1055/s-0041-1732343.

ISSN 2512-9465. (c) 2021. The Author(s).

This is an open access article published by Thieme under the terms of the Creative Commons Attribution License, permitting unrestricted use, distribution, and reproduction so long as the original work is properly cited. (https://creativecommons.org/licenses/by/4.0/)

Georg Thieme Verlag KG, Rüdigerstraße 14, 70469 Stuttgart, Germany 


\section{Introduction}

Rapid reperfusion of the infarct-related artery is the best method to reduce the morbidity and mortality of ST segment elevation myocardial infarction (STEMI). ${ }^{1,2}$ The earlier therapy is initiated the greater the likelihood that the thrombi will be platelet-rich and dynamic, ${ }^{3}$ offering the best opportunity for pharmacological reperfusion.

Studies of oral P2Y12 antagonists administered along with aspirin at the first point of medical care have been disappointing, ${ }^{4-6}$ in part because these agents require several hours to reach maximal effect in STEMI, especially when co-administered with opioids, even when crushed to speed absorption. ${ }^{7-10}$ In contrast, two meta-analyses of studies of early intravenous therapy with the $\alpha$ IIb $\beta 3$ (GPIIb/IIIa) antagonists demonstrated significantly increased perfusion of the infarctrelated artery at the time of percutaneous coronary artery intervention (PCI), even with concurrent clopidogrel therapy, more rapid ST-segment elevation resolution, higher left ventricular ejection fraction, and lower 6-month and long-term mortality. ${ }^{11-19}$ However, these agents require bolus intravenous administration followed by a continuous infusion. Thus, there is a need in the prehospital therapy of STEMI ${ }^{20}$ for a rapidly acting $\alpha \operatorname{Ilb} \beta 3$ antagonist that can be administered subcutaneously (SC) and rapidly achieve high-grade inhibition of platelet function. To decrease the hemorrhagic risk, it would be desirable for the drug's antiplatelet effects to diminish as the antiplatelet effects of the commonly co-administered oral P2Y12 antagonists reach their maximal effects.

RUC-4 is a novel second-generation small-molecule $\alpha$ IIb $\beta 3$ antagonist. It has a unique mechanism of action that locks the receptor in its inactive conformation. ${ }^{21-24}$ In a Phase 1 study conducted in healthy volunteers and stable coronary artery disease patients on aspirin, RUC-4 produced high grade inhibition of ADP $(20 \mu \mathrm{M})$-induced platelet aggregation as measured by light transmission aggregometry (LTA) within 15 minutes of SC administration, with rapid return of platelet function over the next $1-2$ hours. ${ }^{25}$ LTA is considered the established gold standard assay to assess the potency of antiplatelet agents because of its association with clinical outcomes. ${ }^{19,26-31}$

As part of RUC-4's further development in Phase 2 studies of patients with STEMI undergoing emergency PCI, where it is impractical to perform multiple LTA assays, it would be useful to have an easy to perform automated assay to monitor the pharmacodynamics (PD) of the drug's effect and correlate the results with the drug's pharmacokinetics. It is important, however, that the assay correlates with the LTA assay. Moreover, since prehospital treatment with a P2Y12 antagonist is the standard of care in locations where RUC- 4 is being tested, ${ }^{2}$ it would be best to have an assay that can differentiate the effects of RUC-4 from those of the P2Y12 antagonist. In addition, near "real-time" data on the extent of RUC-4-mediated platelet inhibition on arrival in the cardiac catheterization laboratory may be important for the interventionalist to optimize additional adjunctive therapy, or to decide on the feasibility of emergency surgery.

To address this need, we evaluated the potential use of the VerifyNow (VN) assays, which are whole-blood, cartridge- based, and automated, and produce results within 15 minutes of blood draw. ${ }^{32}$ Commercially available VN assays are designed to study the antiplatelet effects of aspirin (VN Aspirin cartridge; arachidonic acid activator) or P2Y12 antagonists (VN PRUTest cartridge and $\mathrm{VN} \quad \mathrm{P} 2 \mathrm{Y} 12$ cartridge; $\mathrm{ADP}+\mathrm{PGE}_{1}$ activator/inhibitor combination). A previously available assay for $\alpha$ IIbß3-mediated platelet inhibition (VN GPIIb/IIla cartridge) was withdrawn from the market, but the modified thrombin receptor activating peptide (iso-TRAP) used in that cartridge is also included in a separate reaction chamber (in addition to the $\mathrm{ADP}+\mathrm{PGE}_{1}$ reaction chamber) in both the PRUTest and P2Y12 cartridges. ${ }^{33-37}$ In addition, a 'base channel' reaction chamber in which iso-TRAP at higher concentrations is combined with a PAR-4 activating peptide (PAR-4 AP) to achieve potent activation that can overcome the effects of P2Y12 antagonists, is available in the P2Y12 assay cartridge. ${ }^{34,35,37}$ To differentiate RUC-4's effects from the effects of P2Y12 antagonists and aspirin, we analyzed the effects of RUC-4, ticagrelor, and aspirin, alone or in combination, on the three different channels.

The choice of anticoagulant is important in assessing the impact of RUC- 4 and other $\alpha I I b \beta 3$ antagonists. Citrate is the most commonly employed anticoagulant for measuring platelet function, ${ }^{39}$ but because it chelates divalent metal ions to below physiologic levels, it enhances the antiplatelet effects of eptifibatide and tirofiban measured by LTA relative to the effects when using anticoagulants that do not chelate divalent cations, such as heparin and phenylalanyl-prolyl-arginyl chloromethyl ketone (PPACK). ${ }^{26,39}$ The use of citrate in early studies of these drugs resulted in an overestimation of their antiplatelet effects and the selection of drug doses that were inadequate to achieve the desired in vivo antithrombotic effect, followed by disappointing clinical efficacy. Adjusting the doses based on studies employing PPACK as the anticoagulant and using $20 \mu \mathrm{M}$ $\mathrm{ADP}$ as the agonist resulted in selection of higher doses that proved clinically effective. ${ }^{26}$ We previously showed that citrate anticoagulation also enhances RUC-4's measured antiplatelet effects. ${ }^{24}$ As a result, in the Phase 1 study of RUC-4, LTA was performed with blood anticoagulated with PPACK. ${ }^{25}$

In the present study, we endeavored to study the effect of RUC-4 and the P2Y12 antagonist ticagrelor in vitro using the $\mathrm{ADP}+\mathrm{PGE}_{1}$, iso-TRAP, and base channel assays in the PRUtest and P2Y12 cartridges. We also studied the effects of different anticoagulants and aspirin on the results, and then compared the data with a measure of receptor occupancy based on competitive binding of RUC- 4 and the activation-dependent monoclonal antibody (mAb) PAC1 $1{ }^{41}$ Finally, we compared these data to those from patients with stable coronary artery disease on aspirin enrolled in the Phase 1 study, who also had measurements of their ADP-induced platelet aggregation by LTA using PPACK-anticoagulated blood.

\section{Methods}

\section{In Vitro Studies}

\section{Blood Collection}

All in vitro studies were approved by the Rockefeller University Institutional Review Board (IRB) and all blood donors 
gave informed consent. Blood from healthy volunteers, who were not taking aspirin, or from volunteers who were taking aspirin that was prescribed for primary or secondary prevention, was obtained via venipuncture with a 19-gauge needle. Blood was anticoagulated with 0.1 volume $3.2 \%$ sodium citrate (final concentration $0.32 \%$ ) or 0.1 volume $1 \mathrm{mM}$ PPACK (final concentration $100 \mu \mathrm{M}$ ) contained in the syringe. Anticoagulated blood to be used for the VN assays (Instrumentation Laboratories, Bedford, MA) was then distributed into 2-mL vacuum tubes (Greiner Bio-One Vacuette, Monroe, NC) that were designed for use with the VN assays. These tubes are supplied with a citrate anticoagulant, and so they were washed with running water 3 times and dried before being used in this study. Whole blood platelet counts and hematocrits were obtained with an automated counter (ADVIA 120 Hematology System, Siemens, Malvern, PA).

\section{Preparation of RUC-4 and Ticagrelor-treated Whole Blood for VN Assays}

$50 \mu \mathrm{L}$ of RUC-4 or ticagrelor stock solution (see - Supplementary Material) was added to $2 \mathrm{~mL}$ of whole blood and VN testing was performed after incubation for 10 minutes at room temperature for RUC- 4 and 30 minutes at $37^{\circ} \mathrm{C}$ for ticagrelor. ${ }^{42}$ All samples were tested within 3 hours of blood drawing.

\section{VN Assays}

In all the VN assays, blood is drawn from the blood collection tube into a cartridge, and then dispensed into separate reaction chambers containing fibrinogen-coated beads and an activator. $^{32}$ The PRUTest cartridge has two active reaction chambers, allowing it to conduct both the ADP $+\mathrm{PGE}_{1}$ and iso-TRAP assays on the same blood sample. The ADP $+\mathrm{PGE}_{1}$ reaction chamber contains ADP at $20 \mu \mathrm{M}$ and prostaglandin $\mathrm{E}_{1}$ $\left(\mathrm{PGE}_{1}\right.$ ) at $0.02 \mu \mathrm{M}$ final concentrations; $\mathrm{PGE}_{1}$ is added to $\mathrm{ADP}$ in the $\mathrm{ADP}+\mathrm{PGE}_{1}$ reaction chamber to increase the specificity of the results for P2Y12-mediated aggregation. ${ }^{33}$ The iso-TRAP channel contains a final concentration of iso-TRAP of 3-4 $\mu \mathrm{M} .{ }^{32,34}$ The P2Y12 cartridge contains in addition to the ADP $+\mathrm{PGE}_{1}$ and iso-TRAP channels, the base channel, which contains $20 \mu \mathrm{M}$ iso-TRAP $+800 \mu \mathrm{M}$ PAR- 4 AP. $^{34,35}$

We also utilized the VN Aspirin cartridge, whose reaction chamber contains arachidonic acid at a final concentration of $1 \mathrm{mM}$, to assess whether blood donors' platelets demonstrated an aspirin effect. ${ }^{33}$

When activated with any of these agonists, platelets bind to the fibrinogen-coated beads and agglutination of the beads and platelets occurs in proportion to the number of available activated platelet receptors. This results in an increase in light transmission, which is reported in arbitrary reaction units. The VN PRUTest and P2Y12 cartridge assays currently only report the results from the $\mathrm{ADP}+\mathrm{PGE}_{1}$ reaction chamber, with the results of the iso-TRAP assay used for internal quality control. ${ }^{35,36}$ The results of the base channel in the P2Y12 cartridge are not reported or used for quality control. Whereas P2Y12 antagonists inhibit the ADP $+\mathrm{PGE}_{1}$ assay but have little or no inhibitory effects on the iso-TRAP assay, $^{38,43}$ the instrument reports an error when there is significant inhibition of the iso-TRAP assay. ${ }^{34,35}$ Thus, blood treated with $\alpha$ IIb $\beta 3$ antagonists, which are potent enough to inhibit the iso-TRAP assay, cannot be tested with the PRUTest or P2Y12 cartridges when the instrument is used with its default settings. However, by connecting the VN instrument to a computer, we were able to collect raw data from all of the reaction chambers of the cartridges and process them by calculating the maximum change in light transmission from the beginning to the end of the assay run time. We expressed the results as reaction units and calculated the percentage inhibition of the assay relative to the control using the equation [1 -(test sample maximum change in light transmittance/ control sample maximal change in light transmittance) $] \times 100$.

\section{Correlation of Percentage of $\alpha$ llb $\beta 3$ Receptors Occupied} by RUC-4 Determined by mAb PAC1 Binding with Both VN Assays and LTA

PAC1 is an IgM mouse mAb that selectively binds to activated $\alpha$ IIb $\beta 3$ in the same region occupied by RUC- $4 .{ }^{41}$ As a result, PAC1 will only bind to activated receptors that are not already occupied by RUC-4, providing information on the percentage of receptors occupied by RUC-4. PPACK-anticoagulated blood was treated with aspirin (0.3 mM) and RUC-4 (concentrations between 0.01 and $0.63 \mu \mathrm{M}$ ). After incubation, aliquots of the samples were tested in the VN assays used for preparing platelet-rich plasma (PRP) for LTA and flow cytometry (see - Supplementary Material).

\section{LTA Studies}

Platelet aggregation was initiated by adding $25 \mu \mathrm{L}$ of agonist to $225 \mu \mathrm{L}$ of PRP and monitored in a PAP-8E aggregometer (BioData Corporation, Horsham, PA) at $37^{\circ} \mathrm{C}$ with stirring. An agonist working stock solution of $200 \mu \mathrm{M}$ ADP was prepared with sterile $0.9 \%$ saline. Platelet aggregation was quantified based on the instrument's measurement of the primary slope (PrSl) of aggregation, which is a measure of the change in light transmission per unit time sustained over at least a 15 second period. The percentage inhibition of the PrSl relative to the control value was calculated as [1-(test PrSl/control PrSl)] X 100. This measure was selected to avoid the need to choose an arbitrary time point for the comparison to baseline, or using the maximal aggregation, which can occur at different time points. Nonetheless, the PrSl correlates well with results based on maximal aggregation and final aggregation in the in vitro studies (-Supplementary Figure S1) and maximal aggregations in the in vivo studies. ${ }^{24}$

\section{In Vivo Studies}

The Phase 1 dose escalation safety and tolerability study of RUC-4 (NCT03844191) was approved by the IRB at The Christ Hospital, Cincinnati, $\mathrm{OH}$. Healthy volunteers or patients with stable coronary artery disease receiving aspirin were enrolled following obtaining informed consent. ${ }^{25}$ RUC- 4 or placebo was administered SC in the deltoid region using a 25 -gauge, $5 / 8$ inch needle attached to a $1 \mathrm{~mL}$ syringe. A subgroup of patients with stable coronary artery disease taking aspirin who received RUC- 4 at a dose of $0.075 \mathrm{mg} / \mathrm{kg}$, had blood collected and prepared for both LTA studies as 
A
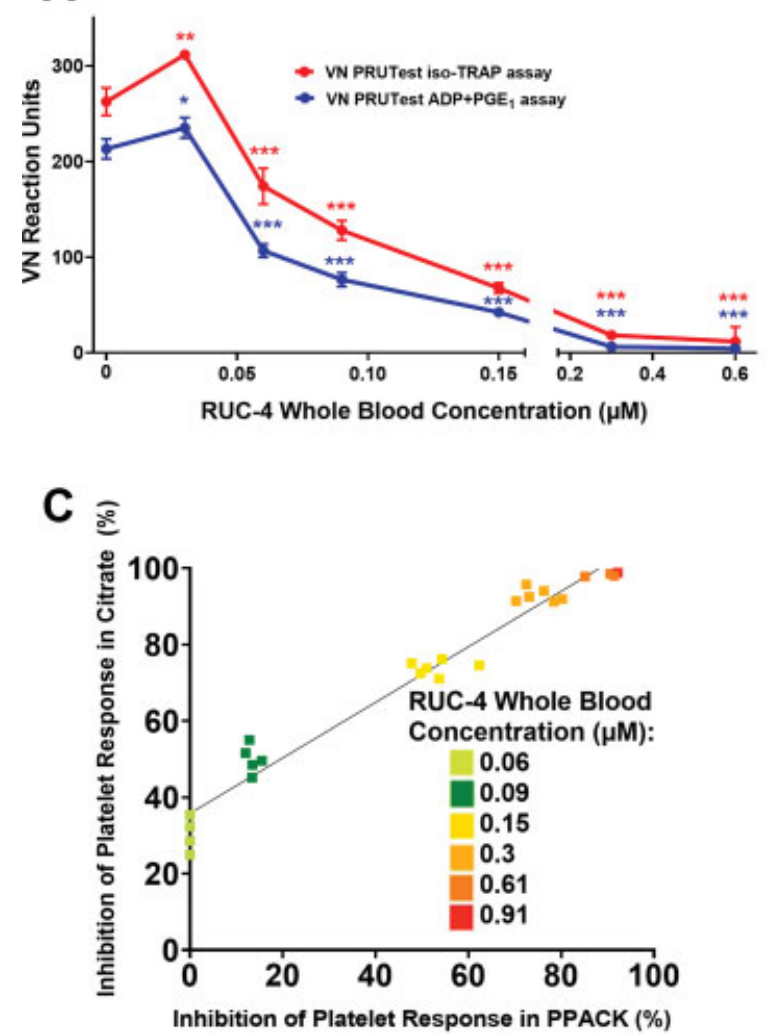

B

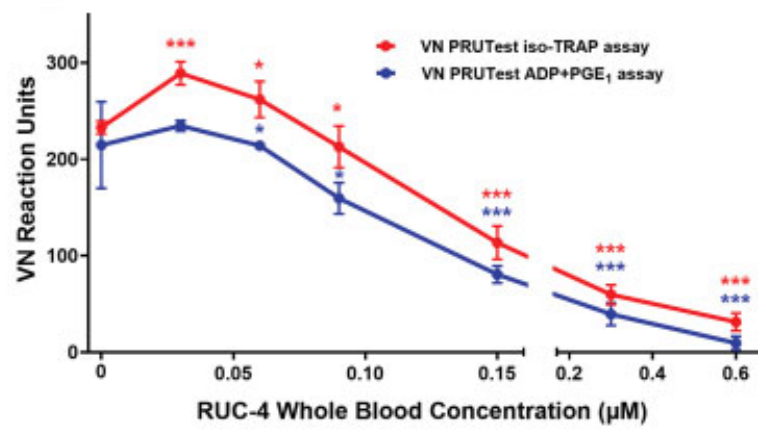

D ฐ

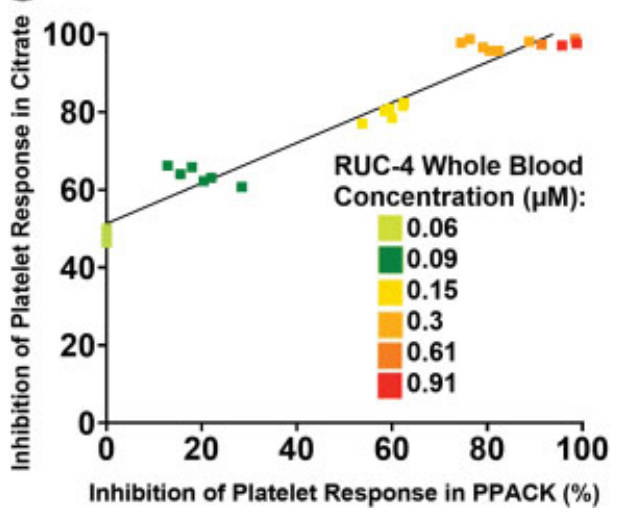

Fig. 1 In vitro RUC-4 concentration-response in inhibiting the VN iso-TRAP and ADP + PGE 1 assays with blood from healthy volunteers not taking aspirin and anticoagulated with sodium citrate or PPACK. (A) Concentration-response curve in citrate-anticoagulated blood ( $n=7)$, data are mean \pm SD. (B) Concentration-response curve in PPACK-anticoagulated blood ( $n=7)$, data are mean \pm SD. (C) Percentage inhibition of response of iso-TRAP assay in PPACK- versus citrate-anticoagulated blood $\left(n=6 ; 25\right.$ measurements; $\left.R^{2}=0.96 ; p<0.001\right)$. (D) Percentage inhibition of response of $\mathrm{ADP}+\mathrm{PGE}_{1}$ assay with PPACK- versus citrate-anticoagulated blood $\left(n=6 ; 25\right.$ measurements; $\left.\mathrm{R}^{2}=0.95 ; p<0.001\right) .{ }^{*} p<0.05$ compared with control, ${ }^{* *} p<0.01$ compared with control, ${ }^{* * *} p<0.001$ compared with control. VN $=$ VerifyNow.

described $^{25}$ and for VN testing. The latter was collected with a 21-gauge needle into 2 -mL sodium citrate vacuum tubes (final concentration 0.32\%; Greiner Bio-One Vacuette). Platelet counts and hematocrits in whole blood and PRP were obtained with an automated counter (Sysmex poc-H100i, Sysmex, Lincolnshire, IL). RUC-4 levels were assayed on $1 \mathrm{~mL}$ samples of whole blood as described. ${ }^{25}$

\section{Data Analysis}

See Supplementary Material.

\section{Results}

\section{In Vitro Studies of RUC-4}

Whole blood samples for the in vitro studies were obtained from 15 healthy volunteers ( 8 males, 7 females) of whom 6 were taking aspirin at a dose of 81 to $325 \mathrm{mg}$ /day. The mean platelet count $\left( \pm\right.$ SD) was $214( \pm 47) \times 10^{3}$ platelets $/ \mu \mathrm{L}$. The antiplatelet effect of aspirin in the 6 participants who were taking aspirin was confirmed with the VN Aspirin assay, with those taking aspirin having values of 401-435 reaction units, all of which are below the cut-off value of 550 reaction units and thus consistent with aspirin-induced inhibition of platelet function, and those not taking aspirin having values of 670-771.
RUC-4 Inhibits Both VN PRUTest Assays (iso-TRAP, ADP $+\mathbf{P G E}_{1}$ ) in a Concentration-dependent Manner, with Citrate-anticoagulated Blood more Sensitive to Inhibition than PPACK-anticoagulated Blood, and the ADP + PGE $_{1}$ Assay more Sensitive to Inhibition than the iso-TRAP Assay

With citrate-anticoagulated blood, the VN PRUTest cartridge iso-TRAP assay reported an $18 \%$ increase in reaction units at the lowest concentration tested compared with baseline $(p<0.01)$ and then progressive and marked inhibition compared with baseline $(p<0.001)$ with higher concentrations ( - Fig. 1A). The $\mathrm{ADP}+\mathrm{PGE}_{1}$ assay reported a $10 \%$ increase at the lowest concentration compared with baseline $(p<0.02)$ with progressive dramatic inhibition compared with baseline with increasing RUC-4 concentrations $(p<0.001)$. With PPACK-anticoagulated blood, the responses were qualitatively similar, with the increase in reaction units with iso-TRAP extending to one higher concentration, and with a progressive decrease in response at higher concentrations (-Fig. 1B). The slope of the concentration-response inhibition with PPACK-anticoagulated blood was less steep than with citrate-anticoagulated blood for both assays at RUC-4 concentrations between 0.03 and $0.06 \mu \mathrm{M}$ (-Fig. 1A,B). For example, at $0.06 \mu \mathrm{M}$ RUC-4 there was no inhibition of the iso-TRAP assay with PPACK-anticoagulated blood compared with $\sim 30 \%$ inhibition with citrate- 
Table $1 \mathrm{IC}_{50} \mathrm{~S}$ (mean \pm SD) of RUC-4 in PPACK- and sodium citrate-anticoagulated blood from volunteers who were either not taking or taking aspirin

\begin{tabular}{|l|l|l|l|l|l|}
\hline \multirow{2}{*}{ VN PRUTest assay } & \multicolumn{2}{|l|}{} & \multicolumn{2}{l|}{$\mathrm{P}$ value } \\
\cline { 2 - 6 } & $\begin{array}{l}\text { PPACK } \\
\text { No aspirin } \\
(1)\end{array}$ & $\begin{array}{l}\text { Citrate } \\
\text { No aspirin } \\
(2)\end{array}$ & $\begin{array}{l}\text { Citrate } \\
\text { Aspirin } \\
(3)\end{array}$ & (1) vs (2) & (2) vs (3) \\
\hline iso-TRAP & $0.14 \pm 0.01$ & $0.09 \pm 0.01$ & $0.10 \pm 0.02$ & $<0.003$ & 0.15 \\
\hline ADP + PGE 1 & $0.12 \pm 0.01$ & $0.07 \pm 0.01$ & $0.08 \pm 0.02$ & $<0.03$ & 0.19 \\
\hline p value & 0.08 & $<0.004$ & $<0.001$ & & \\
\hline
\end{tabular}

Abbreviations: $I C_{50}$, Half maximal inhibitory concentration; VN, VerifyNow.

anticoagulated blood. Similar results were observed with the $\mathrm{ADP}+\mathrm{PGE}_{1}$ assay. Because of these anticoagulant-dependent differences, the $\mathrm{IC}_{50} \mathrm{~S}$ of RUC- 4 were $\sim 40 \%$ lower with citrateanticoagulated blood compared with PPACK-anticoagulated blood ( Table 1). There was, however, a close correlation between the results with the different anticoagulants with both assays at RUC-4 concentrations above $0.06 \mu \mathrm{M}$ ( - Fig. 1C, D; iso-TRAP: $\mathrm{R}^{2}=0.96, p<0.001 ; \mathrm{ADP}+\mathrm{PGE}_{1}: \mathrm{R}^{2}=0.95$, $p<0.001)$. Based on the greater sensitivity of the assays to RUC-4 at low concentrations in citrate-anticoagulated blood and the commercial availability of vacuum tubes for the VN assays containing citrate but not PPACK, we performed additional studies with citrate-anticoagulated blood.

With citrate-anticoagulated blood, the percent inhibition by RUC- 4 correlated closely between the ADP $+\mathrm{PGE}_{1}$ and isoTRAP assays $\left(\mathrm{R}^{2}=0.97, p<0.001\right)$, but the ADP $+\mathrm{PGE}_{1}$ assay was more sensitive as judged by the deviation from the line of identity at lower concentrations (-Supplementary Figure S2), with the $\mathrm{IC}_{50} \sim 20 \%$ lower than that with the iso-TRAP assay (-Table 1, $p<0.004$ ).

\section{Aspirin does not Affect RUC-4's Inhibition of the VN PRUTest Assays}

Since aspirin is the standard of care for STEMI and will be administered along with RUC-4, we tested the effect of aspirin by comparing the in vitro concentration-response to RUC-4 in blood obtained from donors who either were not taking aspirin or taking aspirin. The RUC-4 concentrationresponse curves ( - Supplementary Figure $\mathbf{S 3}$ ) in citrate-anticoagulated blood from individuals who were taking aspirin had similar patterns to those from individuals who were not taking aspirin. Accordingly, the mean $\mathrm{IC}_{50} \mathrm{~S}$ of RUC-4 in citrate-anticoagulated blood were similar in both assays in individuals who were taking aspirin vs individuals who were not taking aspirin ( - Table 1: $p=0.15$ in the iso-TRAP assay and $p=0.19$ in the ADP $+\mathrm{PGE}_{1}$ assay).

\section{RUC-4 Produces Concentration-dependent Occupancy of Platelet $\alpha$ llb $\beta 3$ Receptors that Correlates with Decreased Platelet Aggregation and VN PRUTest Assays' Reaction Units}

We previously reported that incubating whole blood with increasing concentrations of RUC-4 results in a decrease in the ability of PAC1 to bind to ADP-activated platelets, reflecting increased occupancy of $\alpha \operatorname{IIb} \beta 3$ receptors. ${ }^{24}$ In the current study we assessed the effect of RUC-4 on PAC1 binding in parallel studies with both whole blood and PRP and correlated the results with the effects of RUC-4 on the VN PRUTest isoTRAP and ADP $+\mathrm{PGE}_{1}$ assays and on $\operatorname{ADP}(20 \mu \mathrm{M})$-induced LTA of PRP ( - Fig. 2). As receptor occupancy increased, there was increased inhibition of the VNassay and aggregation measured by LTA ( - Fig. 2B). When PRP PAC1 binding was inhibited by $80 \%$ or more, the iso-TRAP assay was inhibited by $71 \%$ ( $71 \pm 49$ reaction units vs $242 \pm 25$ reaction units at baseline; $p<0.001$ ), the $\mathrm{ADP}+\mathrm{PGE}_{1}$ assay was inhibited by $77 \%$ ( $46 \pm 4$ reaction units vs $199 \pm 11$ reaction units at baseline; $p<0.001$ ), and LTA was inhibited by $86 \pm 17 \%$.

\section{In Vivo Studies of RUC-4}

In Vivo Administration of RUC-4 to Patients with Stable Coronary Artery Disease on Aspirin Results in Timedependent Inhibition of Platelet Function Measured by ADP-induced LTA and Both the iso-TRAP and ADP + PGE $_{1}$ VN Assays

Participants with stable coronary artery disease on aspirin in the Phase 1 study of RUC-4 $(n=11$; mean age $66 \pm 7$ years, $58 \%$ male, mean weight $87 \pm 23 \mathrm{~kg}$ ) who received 0.075 $\mathrm{mg} / \mathrm{kg}$ of RUC-4 SC had blood drawn in PPACK (for LTA studies) or into vacuum tubes containing sodium citrate (for VN studies) at timed intervals.

The inhibition of ADP-induced LTA as a function of time after RUC-4 administration is shown in - Fig. $\mathbf{3 A}$ (black line) and is notable for the onset of high-grade inhibition of aggregation by 15 minutes, followed by sustained high-grade inhibition at 30 minutes, and then a return toward baseline over the next two hours. The results of both the VN PRUTest iso-TRAP(red line) and $\mathrm{ADP}+\mathrm{PGE}_{1}$ (blue line) assays at the first four time points are superimposed on the results of the ADP-induced LTA data and show a striking correlation during the first 3 time points. At the fourth time point, the iso-TRAP assay reported less inhibition than the ADP $+\mathrm{PGE}_{1}$ assay, reflecting the greater sensitivity of the latter to lower concentrations of RUC-4.

Inhibition of Both the iso-TRAP and ADP $+\mathrm{PGE}_{1}$ VN Assays Correlates with RUC-4 Blood Concentrations

Blood concentration of RUC-4 up to $0.2 \mu \mathrm{M}$ correlated closely with inhibition of both $\mathrm{VN}$ assays (- Fig. 3B; iso-TRAP assay: $\mathrm{R}^{2}=0.83, p<0.001 ; \mathrm{ADP}+\mathrm{PGE}_{1}$ assay: $\left.\mathrm{R}^{2}=0.81, p<0.001\right)$. At concentrations above $0.2 \mu \mathrm{M}$ the inhibition of the $\mathrm{VN}$ assays leveled off at $91 \pm 8 \%$ for the iso-TRAP assay and $91 \pm 4 \%$ for the $\mathrm{ADP}+\mathrm{PGE}_{1}$ assay. 
A

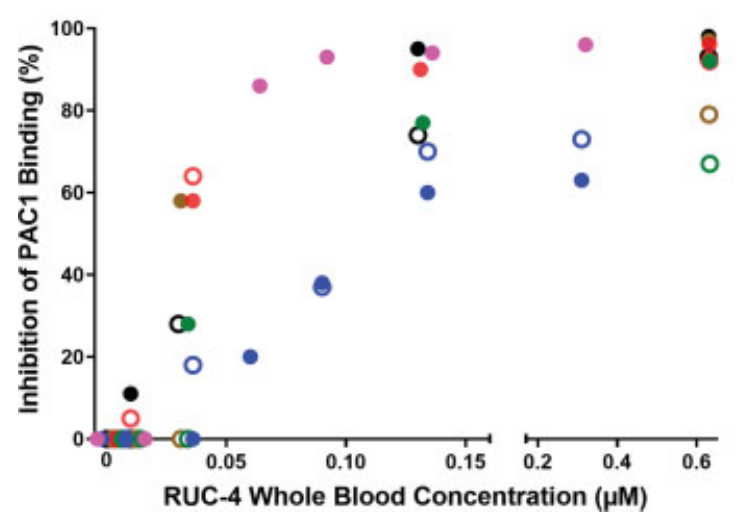

B

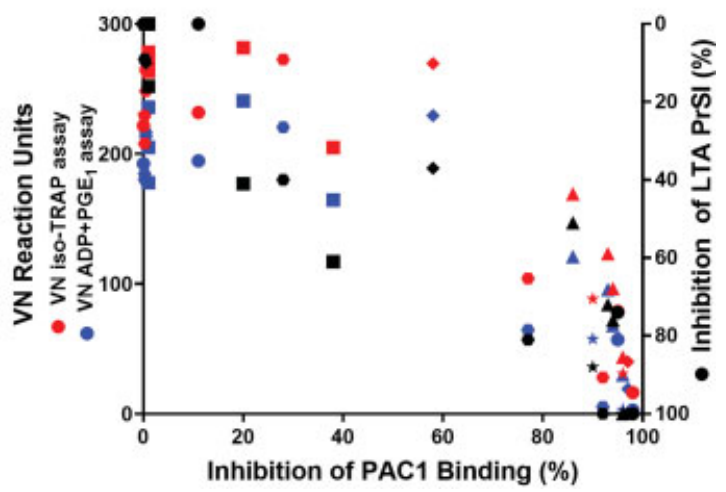

Fig. 2 Correlation of PAC1 binding, reflecting the $\alpha$ IIb $\beta 3$ receptors not occupied by RUC-4, with RUC-4 whole blood concentration and inhibition of the VN and LTA assays in blood anticoagulated with PPACK and treated with aspirin. (A) Percentage inhibition of fluorescently-labeled PAC1 binding to ADP-activated platelets as a function of RUC-4 whole blood concentration. RUC-4 was added to whole blood and then both whole blood (open circles; $n=5 ; 24$ measurements) and PRP prepared from that blood (filled circles; $n=6 ; 30$ measurement) were activated with ADP $(20 \mu \mathrm{M})$ and analyzed by flow cytometry. Each color signifies a different volunteer. (B) Percentage inhibition of PAC1 binding to ADP-activated platelets in PRP versus the 2 different VN assays (left axis) and inhibition of ADP ( $20 \mu \mathrm{M})$-induced LTA PrSI (right axis). Each shape signifies a different volunteer, each color signifies a different assay. VN = VerifyNow; LTA = Light transmission aggregometry; PRP = Platelet-rich plasma; $\mathrm{PrSl}=$ Primary slope.
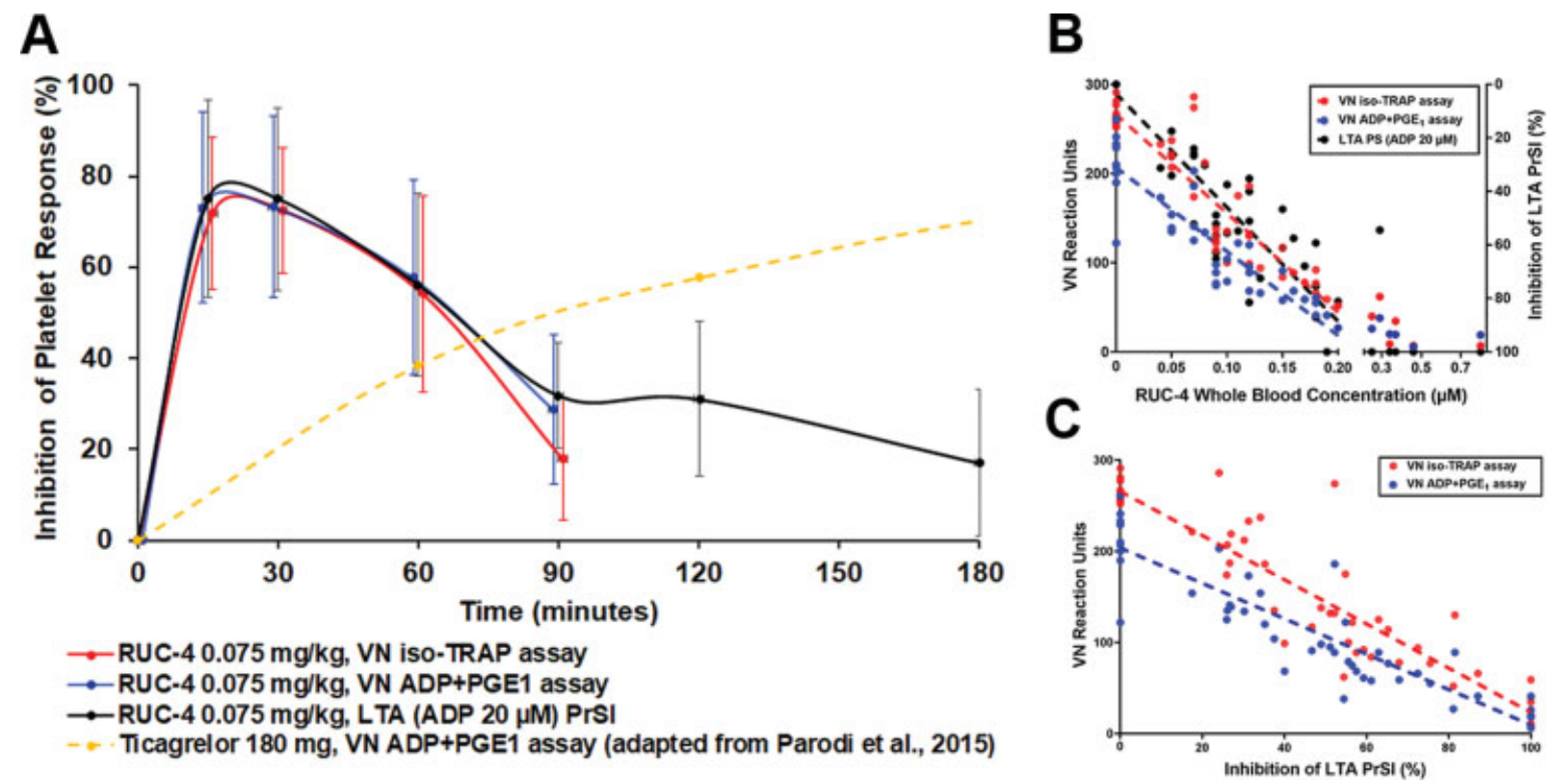

Fig. 3 Inhibition of platelet function measured by the VN iso-TRAP and ADP $+\mathrm{PGE}_{1}$ assays of citrate-anticoagulated blood and ADP-induced LTA of PPACK-anticoagulated blood after RUC-4 subcutaneous administration to humans, and comparison with effect of ticagrelor after oral administration of crushed tablets to STEMI patients reported by Parodi et al., J Am Coll Cardiol 2015; 65: 511-512 (data extracted from figure using WebPlotDigitizer). (A) Inhibition of platelet responses as a function of time after administration of either RUC-4 (mean \pm SD; $n=11,50$ measurements) or ticagrelor (VN ADP $\left.+\mathrm{PGE}_{1} ; n=41\right)$. (B) RUC-4 whole blood concentration versus VN reaction units (left axis) and inhibition of $\operatorname{ADP}(20 \mu \mathrm{M})$-induced LTA PrSI (right axis) (linear regression lines: iso-TRAP assay: $\mathrm{R}^{2}=0.83 ; p<0.001 ; \mathrm{ADP}+\mathrm{PGE}_{1}$ assay: $\mathrm{R}^{2}=0.81 ; p<0.001$; LTA: $R^{2}=0.83 ; p<0.001$. (C) Inhibition of LTA PrSI versus VN reaction units (linear regression lines: iso-TRAP assay: $R^{2}=0.84, p<0.001$; $\mathrm{ADP}+\mathrm{PGE}_{1}$ assay: $\left.\mathrm{R}^{2}=0.83 ; p<0.001\right)$. VN = VerifyNow; LTA = Light transmission aggregometry; PrSI = Primary slope; PRP = Platelet- rich plasma.

VN iso-TRAP Assay Reaction Units Correlate with LTAmeasured Platelet Aggregation in Blood from Individuals Treated with RUC-4

Since RUC-4 will be administered prehospital in its clinical trials, the first VN assay will be obtained after it is adminis- tered. As a result, no baseline value will be available for comparison. Therefore, we assessed the relationship between inhibition of ADP-induced LTA and the absolute reaction units reported by the VN assays and found a close correlation at all time points with each assay ( - Fig. 3 C, 

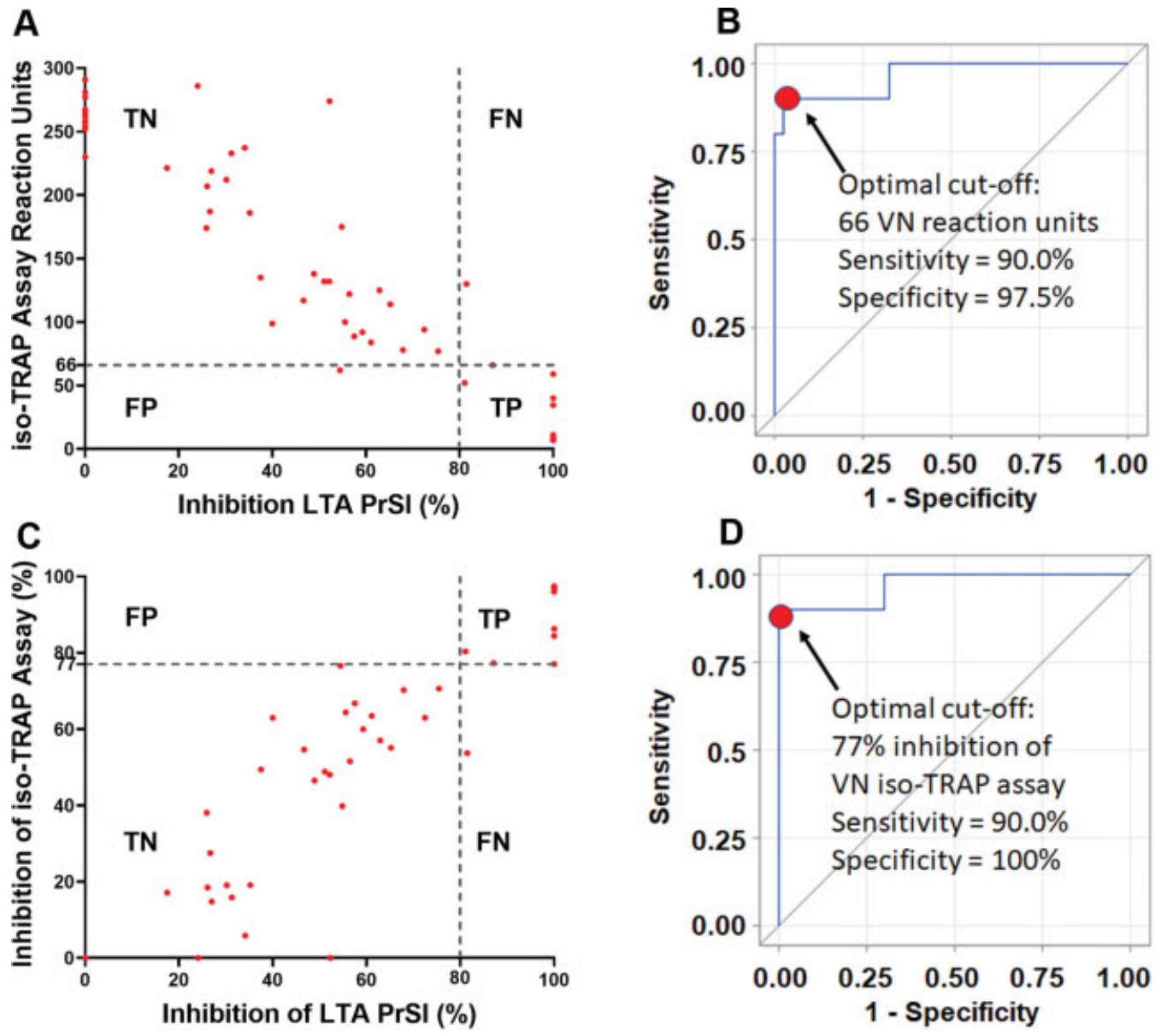

Fig. 4 ROC curves identifying the VN PRUTest iso-TRAP assay reaction units that correspond to $80 \%$ or greater inhibition of the PrSI of ADP (20 $\mu \mathrm{M}$ )-induced LTA in patients on aspirin treated with RUC-4. (A) Reaction unit scatter plot. (B) Reaction unit ROC curve, identifying the optimal cutoff value as 66 reaction units. (C) Percentage inhibition scatter plot. (D) Percentage inhibition ROC curve, identifying the optimal cut-off as $77 \%$. LTA was performed with PRP prepared from PPACK-anticoagulated blood, VN testing was performed with citrate-anticoagulated blood. $n=11$ donors, 50 measurements. $\mathrm{ROC}=$ Receiver operating characteristic; $\mathrm{VN}=$ VerifyNow; PrSI = Primary Slope; LTA = Light transmission aggregometry; PRP = Platelet-rich plasma.

iso-TRAP assay: $\mathrm{R}^{2}=0.84, p<0.001, \mathrm{ADP}+\mathrm{PGE}_{1}$ assay: $\mathrm{R}^{2}=0.83, p<0.001$ ). When ADP-induced LTA was inhibited by $\geq 80 \%$, the mean ( \pm SD) VN reaction units measured with the iso-TRAP and ADP $+\mathrm{PGE}_{1}$ assays were $43 \pm 38$ and $31 \pm 23$, respectively.

\section{Receiver Operating Characteristic Curve Analysis for} Identifying the Optimal Cut-off Point for Monitoring RUC4 Therapy with the VN Assays

We used ROC curves of the absolute reaction units and the percentage inhibition of the VN assays to identify the optimal cut-off points for assessing the PD of RUC-4, with the binary classifier set at $80 \%$ inhibition of ADP-induced LTA. Correlated observations within subjects were accounted for by using a mixed effects logistic regression model. The Area Under the Curve (AUC) for the ROC curves was 0.97 (95\% CI 0.9-1.0). The optimal iso-TRAP assay reaction unit cut-off point in citrate-anticoagulated blood for detecting $\geq 80 \%$ inhibition of LTA-measured platelet aggregation in PRP prepared from PPACK-anticoagulated blood was $\leq 66$ reaction units (sensitivity $=90.0 \%$, specificity $=97.5 \%$ ), which corresponded to $\geq 77 \%$ inhibition (sensitivity $=90.0 \%$, specificity $=100 \%)(-$ Fig. 4).

Hematocrit did not Significantly Affect either VN Assay A low hematocrit has been associated with higher reaction unit values with both the ADP $+\mathrm{PGE}_{1}{ }^{44-50}$ and iso-TRAP ${ }^{49,50}$ assays in blood samples from untreated individuals and individuals treated with clopidogrel. In our study, the mean $( \pm S D)$ hematocrits at baseline in the in vitro and in vivo cohorts were $42 \pm 4 \%$ (range: $34-51$ ) and $42 \pm 3 \%$ (range: $35-47$ ), respectively. The plot of baseline readings of the VN assays vs hematocrit showed minor positive correlations (iso-TRAP assay: $\mathrm{R}^{2}=0.13, p=0.08 ; \mathrm{ADP}+\mathrm{PGE}_{1}$ assay: $\left.\mathrm{R}^{2}=0.16, p<0.04\right)$ and thus we did not observe an inverse relationship between hematocrit and $\mathrm{VN}$ reaction units across the range of hematocrits in the individuals we studied (-Supplementary Figure S4). 


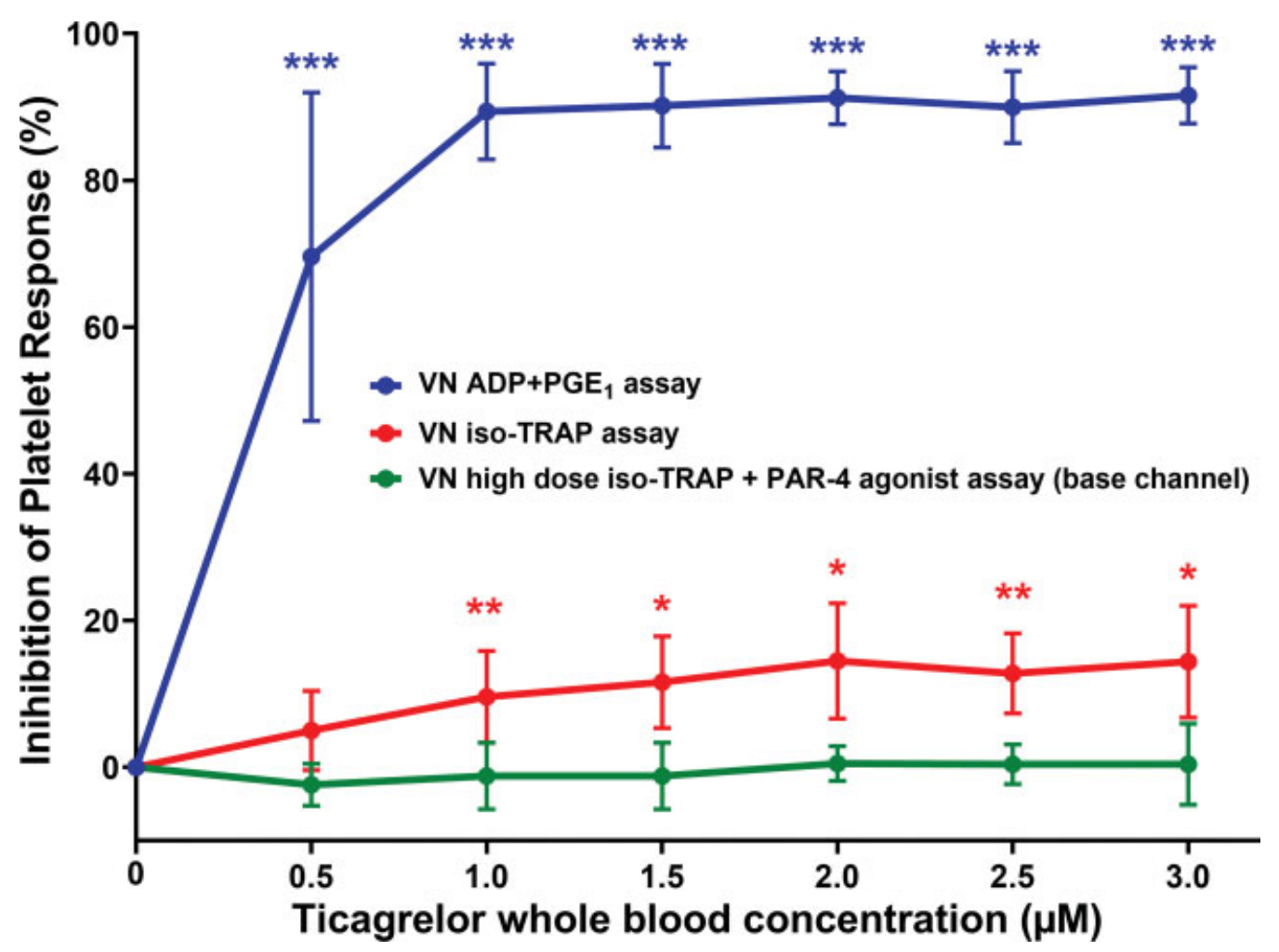

Fig. 5 Effect of in vitro addition of ticagrelor on the VN iso-TRAP, ADP + $\mathrm{PGE}_{1}$, and base channel assays, $n=5,34$ measurements, data are mean \pm SD. All experiments were performed with citrate-anticoagulated blood from healthy donors who were not taking aspirin. ${ }^{*} p<0.05$ compared with control, ${ }^{* *} p<0.01$ compared with control, ${ }^{* * *} p<0.001$ compared with control. VN $=$ VerifyNow. PAR-4 AP $=$ PAR-4 activating peptide.

\section{In Vitro Studies of Ticagrelor}

RUC-4's Pharmacodynamics Complement Those of Ticagrelor

-Fig. 3A shows the VN PRUTest ADP $+\mathrm{PGE}_{1}$ assay results in the Phase 1 study as a function of time after RUC- 4 administration superimposed on the results reported by Parodi et al. using the VN ADP $+\mathrm{PGE}_{1}$ assay in their study of 41 patients with STEMI who received a $180 \mathrm{mg}$ loading dose of ticagrelor as crushed tablets. ${ }^{7}$ Thus, if given together, our data suggest that RUC-4's effects will begin to wear off as the effects of ticagrelor become more apparent, with the latter beginning to plateau after approximately two hours.

Ticagrelor Produces Less than $20 \%$ Inhibition of the VN iso-TRAP Assay at Concentrations that Inhibit the $\mathrm{ADP}+\mathrm{PGE}_{1}$ Assay by $80 \%$ or More; the VN Base Channel Assay is Unaffected by Ticagrelor

In RUC-4 clinical studies, patients may receive concurrent treatment with aspirin, RUC-4, and a P2Y12 antagonist. In these cases the VN ADP + PGE $_{1}$ assay will be inhibited by both RUC-4 and the P2Y12 antagonist, but not aspirin. Thus, we assessed the potential impact of ticagrelor on the assays. Concentration-response experiments with ticagrelor were performed in VN P2Y12 cartridges. While the ADP $+\mathrm{PGE}_{1}$ assay was inhibited even at the lowest concentration, $0.5 \mu \mathrm{M}$, the iso-TRAP and base channel assays were minimally affect- ed or unaffected, respectively (-Fig. 5). Incubating citrateanticoagulated whole blood with ticagrelor at $1.5 \mu \mathrm{M}$, a concentration representing the sum of the average peak plasma concentrations of ticagrelor and its active metabolite attained in vivo after a $180 \mathrm{mg}$ loading dose (1.96-2.87 $\mu \mathrm{M}),{ }^{8,9,51,52}$ resulted in a $90 \pm 6 \%$ reduction of the ADP + $\mathrm{PGE}_{1}$ assay $(p<0.001), 12 \pm 6 \%$ reduction of the iso-TRAP assay $(p<0.05)$, and no reduction of the base channel assay $(p=0.53)$.

In the Absence of Ticagrelor, the VN iso-TRAP and Base Channel Assays are Inhibited Similarly by Increasing Concentrations of RUC-4

We directly compared the sensitivity of the iso-TRAP and base channel assays to inhibition by RUC- 4 by adding increasing concentrations of RUC-4 to blood from three donors who were not taking aspirin and measuring the impact on both assays in the same P2Y12 cartridge. The sensitivity of the assays was similar (- Fig. 6), with both showing $\geq 77 \%$ inhibition at concentrations $\geq 0.15 \mu \mathrm{M}$. We then determined the base channel reaction unit value that is equivalent to the iso-TRAP 66 reaction unit value that we found corresponds to $80 \%$ inhibition of ADP-induced LTA, and found the value to be 62 reaction units by linear regression analysis. Thus, achieving a base channel assay value of 62 reaction units or less indicates that the treatment has achieved the inhibition of platelet function associated with improved in vivo outcomes in PCI for STEMI. ${ }^{26}$ 


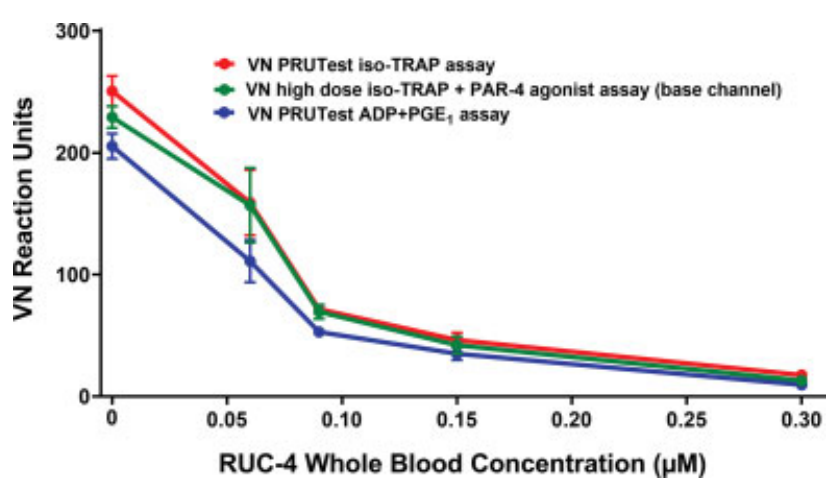

Fig. 6 In vitro RUC-4 concentration-response in inhibiting the VN isoTRAP and base channel assays with blood from healthy volunteers not taking aspirin and anticoagulated with sodium citrate, $n=3,15$ measurements, data are mean $\pm S D$. $V N=$ VerifyNow.

\section{Discussion}

Our data indicate that the VN assays may provide valuable PD data during the development of RUC-4 for prehospital therapy of STEMI because: 1 . RUC-4 produces in vitro and in vivo concentration-dependent inhibition of platelet function measured by the ADP $+\mathrm{PGE}_{1}$, iso-TRAP, and base channel assays. 2. Aspirin does not affect any of the assays, nor does it affect the impact of RUC-4 on the assays. 3. Citrate anticoagulation enhances the sensitivity of the assays to the effects of RUC-4. 4. The ADP $+\mathrm{PGE}_{1}$ assay is more sensitive to low concentrations of RUC- 4 than the 2 iso-TRAP-based assays. 5. There is a strong correlation between blood concentrations of RUC- 4 and $\alpha$ IIb $\beta 3$ occupancy, inhibition of ADP-induced LTA, and inhibition of the VN assays. 6. The predicted equivalent of $\geq 80 \%$ inhibition of platelet aggregation induced by $20 \mu \mathrm{M}$ ADP in PRP made from PPACK-anticoagulated blood, the established standard for predicting $\alpha \operatorname{Ilb} \beta 3$ antithrombotic clinical efficacy, ${ }^{26}$ is $\leq 66$ reaction units in the iso-TRAP assay and $\leq 62$ reaction units in the base channel assay. 7. The iso-TRAP assay is much less sensitive to the effects of ticagrelor than the $\mathrm{ADP}+\mathrm{PGE}_{1}$ assay, but it is partially affected at the highest ticagrelor concentrations achieved in vivo. In sharp contrast, and in accord with studies using the potent P2Y12 antagonist prasugrel, ${ }^{38}$ the base channel assay is not affected by even the peak concentrations of ticagrelor likely to be achieved in vivo.

Although our data were developed to facilitate the PD assessment of RUC-4 during its clinical development, our findings may be generalizable to clinical monitoring of RUC-4 therapy if it is approved for treating STEMI. The results may be valuable to the interventionalist performing the PCI, especially if there is consideration of the need for additional $\alpha \operatorname{IIb} \beta 3$ antagonist therapy on the one hand, or if there is consideration of emergency coronary artery bypass surgery on the other hand. Moreover, the assays can be used in concert to assess when the effect of RUC- 4 wears off (using the base channel or iso-TAP assay if a P2Y12 antagonist was not already administered or the base channel assay if a P2Y12 antagonist was already administered), and at that point monitor the onset and/or extent of platelet inhibition by any co-administered P2Y12 antagonist. Since patients will not have baseline VN assay values when treated at firstpoint-of-contact, we established the optimal iso-TRAP and base channel cut-off value based on absolute reaction units rather than percentage inhibition so that one can assess whether RUC- 4 achieved a level of platelet inhibition associated with improved clinical outcomes in patients with STEMI.

The limitations of our study include the following: 1. Our experiments used blood from healthy volunteers or volunteers with stable coronary artery disease, and as such it remains to be established whether the results will be similar in the clinical scenarios of in vivo administration of antiplatelet drugs in patients with acute coronary syndromes. Similarly, results of our experiments with in vitro ticagrelor administration may not be extrapolatable to in vivo use of ticagrelor, or of other P2Y12 antagonists, including prasugrel, which may have benefits over ticagrelor in acute coronary syndromes. ${ }^{1}$ Data from the Phase $2 \mathrm{~A}$ study of RUC-4 administered to patients with STEMI who were also treated with heparin, aspirin, and ticagrelor demonstrated a similar relationship between RUC-4 whole blood levels and inhibition of the VN assays as we observed, supporting the potential applicability of the assays in monitoring STEMI patients, even in the presence of these other drugs. ${ }^{53}$ 2. Although we did not observe the reported inverse relationship between hematocrit and $\mathrm{VN}$ reaction units, the limited range of hematocrits in the participants in our study may have limited our ability to observe a difference. As a result, hematocrit correction may be required in a population with a wider range of hematocrits. 3 . We were able to extract the iso-TRAP and base channel data from the commercial VN assays using a computer, but these are not currently reported by the instrument. Thus, to make this information available to clinicians who would like to monitor the antiplatelet impact of RUC- 4 or any other $\alpha$ IIb $\beta 3$ antagonist alone or in concert with a P2Y12 antagonist, the manufacturer will have to obtain regulatory approval for reporting the results of the iso-TRAP and/or base channel assays. 4 . We studied the VN assays because we are familiar with their use, but other point-of-care assays to monitor antiplatelet therapy may also be able to provide similar information. 5. The potential of RUC-4 to produce an increased risk of bleeding is likely to be the major factor in assessing its safety. RUC-4's short duration of antiplatelet effects was designed to reduce the hemorrhagic risks, with its highest grade inhibition of platelet function wearing off before instrumentation to perform PCI and at the time of sheath removal. Since there was no association between bleeding risk and inhibition of an earlier version of the isoTRAP assay in the GOLD study, ${ }^{19} \mathrm{VN}$ assays are unlikely to be valuable in assessing hemorrhagic risk.

In summary, the VN assays can be used to assess the pharmacodynamics of RUC-4 during its development and potentially in the future to monitor it or other $\alpha \operatorname{IIb} \beta 3$ antagonists in the presence of a P2Y12 antagonist. In patients 
who only receive aspirin and RUC- 4 or another $\alpha \operatorname{IIb} \beta 3$ antagonist, any of the VN assays can provide valuable information. If ticagrelor or another P2Y12 antagonist is administered at the same time as RUC- 4 or another $\alpha \operatorname{IIb} \beta 3$ antagonist, the combination of assays allows for differentiating the relative contributions of each drug.

\section{What is known on this Topic?}

1. Prehospital therapy of ST-elevation myocardial infarction (STEMI) with $\alpha$ IIb $\beta 3$ antagonists improves clinical outcomes.

2. RUC- 4 is a novel subcutaneous $\alpha$ IIb $\beta 3$ antagonist designed for first-point-of-contact therapy of STEMI.

3. The established standard measure of antiplatelet effect is light transmission aggregometry (LTA), but LTA is difficult to perform during STEMI treatment; LTA is also confounded by the presence of multiple antiplatelet agents, such as aspirin, ticagrelor, and an $\alpha \mathrm{IIb} \beta 3$ antagonist.

\section{What does this Paper Add?}

1. VerifyNow (VN) ADP $+\mathrm{PGE}_{1}$, iso-TRAP, and base channel (high concentration iso-TRAP + PAR-4 agonist) assays report RUC-4-mediated inhibition in near real-time.

2. RUC-4 dramatically inhibits all 3 VNassays, whereas aspirin does not inhibit the assays, and ticagrelor dramatically inhibits the $\mathrm{ADP}+\mathrm{PGE}_{1}$ assay, slightly inhibits the isoTRAP assay, and does not inhibit the base channel assay.

3. VN assays can be used to help differentiate the antiplatelet effects of $\alpha \mathrm{IIb} \beta 3$ antagonists vs P2Y12 antagonists.

\section{Author Contributions}

O. S. Bentur contributed concept/design, designed, and conducted the in vitro experiments, analyzed the data, drafted the article, and critically revised the article. J. Li designed and provided training on the PAC1 binding assay. C. S. Jiang analyzed and interpreted the data. L. H. Martin participated in the planning and carrying out of the phase I study. D. J. Kereiakes was the principal investigator of the RUC-4 phase I study and critically reviewed the article. B. S. Coller conceived and oversaw the project, drafted the article, critically revised the article, and approved the article.

\section{Funding}

B.S.C is supported by grant 19278 from the National Heart, Lung and Blood Institute and funds from Stony Brook University. B.S.C and O.S.B are supported by grant UL1 TR001866 from the National Center for Advancing Translational Sciences, National Institutes of Health. The RUC-4 Phase I study was funded by CeleCor Therapeutics. CeleCor Therapeutics supplied RUC-4, the VerifyNow assay instrument and the cartridges and tubes used in this study.

\section{Conflict of Interest}

B.S.C receives royalties from Instrumentation Laboratories on the sales of the cartridges for the VerifyNow PRUTest assay. He is also an inventor of RUC-4, a founder and equity holder in CeleCor Therapeutics, the company to which RUC-4 has been licensed by Rockefeller University, and a consultant to CeleCor.

\section{Acknowledgments}

The authors would like to acknowledge Robert S. Hillman and Cory McCluskey for support in extracting and analyzing the data from the VerifyNow device and Spandana Vootukuri for advice in performing preliminary studies with the VerifyNow assays.

\section{References}

1 Collet J-P, Thiele H, Barbato E, Barbato E, et al. 2020 ESC Guidelines for the management of acute coronary syndromes in patients presenting without persistent ST-segment elevation. Eur. Heart J 2021;42(14):1289-1367

2 Ibanez B, James S, Agewall S, et al; ESC Scientific Document Group. 2017 ESC Guidelines for the management of acute myocardial infarction in patients presenting with ST-segment elevation: The Task Force for the management of acute myocardial infarction in patients presenting with ST-segment elevation of the European Society of Cardiology (ESC). Eur Heart J 2018;39(02):119-177

3 Silvain J, Collet JP, Nagaswami C, et al. Composition of coronary thrombus in acute myocardial infarction. J Am Coll Cardiol 2011; 57(12):1359-1367

4 Montalescot G, van 't Hof AW, Lapostolle F, et al; ATLANTIC Investigators. Prehospital ticagrelor in ST-segment elevation myocardial infarction. N Engl J Med 2014;371(11):1016-1027

5 Bellemain-Appaix A, O'Connor SA, Silvain J, et al; ACTION Group. Association of clopidogrel pretreatment with mortality, cardiovascular events, and major bleeding among patients undergoing percutaneous coronary intervention: a systematic review and meta-analysis. JAMA 2012;308(23):2507-2516

6 Zeymer U, Arntz HR, Mark B, et al. Efficacy and safety of a high loading dose of clopidogrel administered prehospitally to improve primary percutaneous coronary intervention in acute myocardial infarction: the randomized CIPAMI trial. Clin Res Cardiol 2012;101(04):305-312

7 Parodi G, Xanthopoulou I, Bellandi B, et al. Ticagrelor crushed tablets administration in STEMI patients: the MOJITO study. J Am Coll Cardiol 2015;65(05):511-512

8 Teng R. Ticagrelor: pharmacokinetic, pharmacodynamic and pharmacogenetic profile: an update. Clin Pharmacokinet 2015; 54(11):1125-1138

9 Butler K, Teng R. Pharmacokinetics, pharmacodynamics, safety and tolerability of multiple ascending doses of ticagrelor in healthy volunteers. Br J Clin Pharmacol 2010;70(01):65-77

10 Tavenier AH, Hermanides RS, Fabris E, Angiolillo DJ, van 't Hof AWJ. Bridging the gap: Current and future insights for improving suboptimal platelet inhibition in STEMI. Int J Cardiol 2021; 328:40-45

11 De Luca G, Van't Hof AW, Gibson CM, et al; EGYPT cooperation. Impact of time from symptom onset to drug administration on outcome in patients undergoing glycoprotein IIb-IIla facilitated primary angioplasty (from the EGYPT cooperation). Am J Cardiol 2015;115(06):711-715

12 Hassan AKM, Liem SS, van der Kley F, et al. In-ambulance abciximab administration in STEMI patients prior to primary $\mathrm{PCI}$ is associated with smaller infarct size, improved LV function and lower incidence of heart failure: results from the Leiden 
MISSION! acute myocardial infarction treatment optimization program. Catheter Cardiovasc Interv 2009;74(02):335-343

13 Herrmann HC, Lu J, Brodie BR, et al; FINESSE Investigators. Benefit of facilitated percutaneous coronary intervention in high-risk STsegment elevation myocardial infarction patients presenting to nonpercutaneous coronary intervention hospitals. JACC Cardiovasc Interv 2009;2(10):917-924

14 Maioli M, Bellandi F, Leoncini M, Toso A, Dabizzi RP. Randomized early versus late abciximab in acute myocardial infarction treated with primary coronary intervention (RELAx-AMI Trial). J Am Coll Cardiol 2007;49(14):1517-1524

15 Van't Hof AW, Ten Berg J, Heestermans T, et al; Ongoing Tirofiban In Myocardial infarction Evaluation (On-TIME) 2 study group. Prehospital initiation of tirofiban in patients with ST-elevation myocardial infarction undergoing primary angioplasty (On-TIME 2): a multicentre, double-blind, randomised controlled trial. Lancet 2008;372(9638):537-546

16 Rakowski T, Zalewski J, Legutko J, et al. Early abciximab administration before primary percutaneous coronary intervention improves infarct-related artery patency and left ventricular function in high-risk patients with anterior wall myocardial infarction: a randomized study. Am Heart J 2007;153(03):360-365

17 Xu Q Yin J, Si LY. Efficacy and safety of early versus late glycoprotein IIb/IIIa inhibitors for PCI. Int J Cardiol 2013;162(03):210-219

18 De Luca G, Bellandi F, Huber K, et al. Early glycoprotein IIb-IIIa inhibitors in primary angioplasty-abciximab long-term results (EGYPT-ALT) cooperation: individual patient's data meta-analysis. J Thromb Haemost 2011;9(12):2361-2370

19 Steinhubl SR, Talley JD, Braden GA, et al. Point-of-care measured platelet inhibition correlates with a reduced risk of an adverse cardiac event after percutaneous coronary intervention: results of the GOLD (AU-Assessing Ultegra) multicenter study. Circulation 2001;103(21):2572-2578

20 Bates ER, Jacobs AK. Time to treatment in patients with STEMI. N Engl J Med 2013;369(10):889-892

21 Zhu J, Choi W-S, McCoy JG, et al. Structure-guided design of a high-affinity platelet integrin $\alpha \operatorname{IIb} \beta 3$ receptor antagonist that disrupts $\mathrm{Mg}^{2+}$ binding to the MIDAS. Sci Transl Med 2012;4 (125): $125 \mathrm{ra} 32$

22 Li J, Vootukuri S, Shang Y, et al. RUC-4: a novel $\alpha$ IIb $\beta 3$ antagonist for prehospital therapy of myocardial in farction. Arterioscler Thromb Vasc Biol 2014;34(10):2321-2329

23 Blue R, Murcia M, Karan C, Jirousková M, Coller BS. Application of high-throughput screening to identify a novel alphallb-specific small- molecule inhibitor of alphaIIbbeta3-mediated platelet interaction with fibrinogen. Blood 2008;111(03):1248-1256

24 Vootukuri S, Li J, Nedelman M, et al. Preclinical studies of RUC-4, a novel platelet $\alpha \operatorname{Ilb} \beta 3$ antagonist, in non-human primates and with human platelets. J Clin Transl Sci 2019;3(2-3):65-74

25 Kereiakes DJ, Henry TD, DeMaria AN, et al. First human use of RUC4: A nonactivating second-generation small-molecule platelet glycoprotein IIb/IIIa (Integrin $\alpha$ IIb $\beta 3$ ) inhibitor designed for subcutaneous point-of-care treatment of ST-Segment-Elevation myocardial infarction. J Am Heart Assoc 2020;9(17):e016552

26 Jennings LK, Jacoski MV, White MM. The pharmacodynamics of parenteral glycoprotein IIb/IIIa inhibitors. J Interv Cardiol 2002; 15(01):45-60

27 Saucedo JF, Lui HK, Garza L, Guerra GJ, Jacoski MV, Jennings LK. Comparative pharmacodynamic evaluation of eptifibatide and abciximab in patients with non-ST-segment elevation acute coronary syndromes: the TAM2 study. J Thromb Thrombolysis 2004;18(02):67-74

28 Gilchrist IC, O'Shea JC, Kosoglou T, et al. Pharmacodynamics and pharmacokinetics of higher-dose, double-bolus eptifibatide in percutaneous coronary intervention. Circulation 2001;104(04): 406-411

29 Tardiff BE, Jennings LK, Harrington RA, et al; PERIGEE Investigators. Pharmacodynamics and pharmacokinetics of eptifibatide in patients with acute coronary syndromes: prospective analysis from PURSUIT. Circulation 2001;104(04):399-405

30 ESPRIT Investigators. Enhanced Suppression of the Platelet IIb/IIIa Receptor with Integrilin Therapy. Novel dosing regimen of eptifibatide in planned coronary stent implantation (ESPRIT): a randomised, placebo-controlled trial. Lancet 2000;356 (9247):2037-2044

31 Steinhubl SR, Kottke-Marchant K, Moliterno DJ, et al. Attainment and maintenance of platelet inhibition through standard dosing of abciximab in diabetic and nondiabetic patients undergoing percutaneous coronary intervention. Circulation 1999;100(19): 1977-1982

32 Smith JW, Steinhubl SR, Lincoff AM, et al. Rapid platelet-function assay: an automated and quantitative cartridge-based method. Circulation 1999;99(05):620-625

33 van Werkum JW, Harmsze AM, Elsenberg EHAM, Bouman HJ, ten Berg JM, Hackeng CM. The use of the VerifyNow system to monitor antiplatelet therapy: a review of the current evidence. Platelets 2008;19(07):479-488

34 FDA 510(k) SUBSTANTIAL EQUIVALENCE DETERMINATION DECISION SUMMARY K141427. Accessed May 24, 2021.https://www. accessdata.fda.gov/cdrh_docs/reviews/K141427.pdf

35 Instrumentation Laboratory. VerifyNow PRUTest Platelet Reactivity Test Instructions For use. Accessed May 24, 2021. https:// www.instrumentationlaboratory.com/

36 Instrumentation Laboratory. VerifyNow P2Y12 Platelet Reactivity Test (OUS only) Instruction For use. Accessed May 24, 2021. https://www.instrumentationlaboratory.com/

37 Coller BS, Springer KT, Scudder LE, Kutok JL, Ceruso M, Prestwich GD. Substituting isoserine for serine in the thrombin receptor activation peptide SFLLRN confers resistance to aminopeptidase M-induced cleavage and inactivation. J Biol Chem 1993;268(28): 20741-20743

38 Jakubowski JA, Zhou C, Egan B, et al. Modification of the VerifyNow ${ }^{\circledR}$ P2Y12 test BASE channel to accommodate high levels of P2Y(12) antagonism. Platelets 2011;22(08):619-625

39 Cattaneo M, Cerletti C, Harrison P, et al. Recommendations for the Standardization of Light Transmission Aggregometry: A Consensus of the Working Party from the Platelet Physiology Subcommittee of SSC/ISTH. J Thromb Haemost 2013;11:1183-1189

40 Kereiakes DJ, Lorenz T, Young JJ, et al. Differential effects of citrate versus PPACK anticoagulation on measured platelet inhibition by abciximab, eptifibatide and tirofiban. J Thromb Thrombolysis 2001;12(02):123-127

41 Shattil SJ, Hoxie JA, Cunningham M, Brass LF. Changes in the platelet membrane glycoprotein IIb.IIIa complex during platelet activation. J Biol Chem 1985;260(20):11107-11114

42 Gerrits AJ, Jakubowski JA, Sugidachi A, Michelson AD, Frelinger AL III. Incomplete reversibility of platelet inhibition following prolonged exposure to ticagrelor. J Thromb Haemost 2017;15(05):858-867

43 Varenhorst C, James S, Erlinge D, et al. Assessment of P2Y(12) inhibition with the point-of-care device VerifyNow P2Y12 in patients treated with prasugrel or clopidogrel coadministered with aspirin. Am Heart J 2009;157(03):562.e1-562.e9

44 Pendyala LK, Loh JP, Lhermusier T, et al. Does baseline hematocrit influence the assays of on-treatment platelet reactivity to clopidogrel? Am Heart J 2014;168(04):545-551

45 Kim YG, Suh JW, Park JJ, et al. Different influences of hematocrit on the results of two Point-Of-Care platelet function tests, the VerifyNow assay and multiple electrode platelet aggregometry. PLoS One 2014;9(11):e114053

46 Janssen PWA, Bergmeijer TO, Godschalk TC, et al. The effect of correcting VerifyNow P2Y12 assay results for hematocrit in patients undergoing percutaneous coronary interventions. J Thromb Haemost 2017;15(04):618-623

47 Toma C, Zahr F, Moguilanski D, et al. Impact of anemia on platelet response to clopidogrel in patients undergoing percutaneous coronary stenting. Am J Cardiol 2012;109(08):1148-1153 
48 Choi SY, Kim MH. Comparison of factors affecting platelet reactivity in various platelet function tests. Platelets 2019;30(05): 631-636

49 Elsenberg EHAM, van Werkum JW, van de Wal RMA, et al. The influence of clinical characteristics, laboratory and inflammatory markers on 'high on-treatment platelet reactivity' as measured with different platelet function tests. Thromb Haemost 2009;102 (04):719-727

50 Kakouros N, Kickler TS, Laws KM, Rade JJ. Hematocrit alters VerifyNow P2Y12 assay results independently of intrinsic platelet reactivity and clopidogrel responsiveness. J Thromb Haemost 2013;11(10):1814-1822

51 Husted S, Emanuelsson H, Heptinstall S, Sandset PM, Wickens M, Peters G. Pharmacodynamics, pharmacokinetics, and safe- ty of the oral reversible P2Y12 antagonist AZD6140 with aspirin in patients with atherosclerosis: a double-blind comparison to clopidogrel with aspirin. Eur Heart J 2006;27(09): 1038-1047

52 Storey RF, Husted S, Harrington RA, et al. Inhibition of platelet aggregation by AZD6140, a reversible oral P2Y12 receptor antagonist, compared with clopidogrel in patients with acute coronary syndromes. J Am Coll Cardiol 2007;50(19): 1852-1856

53 Bor WL, Zheng KL, Tavenier AH, et al. Pharmacokinetics, pharmacodynamics, and tolerability of subcutaneous administration of a novel glycoprotein IIb/IIIa inhibitor, RUC-4, in patients with STsegment elevation myocardial infarction. EuroIntervention 2021; $17: 401-410$ 